\title{
A ladainha e a Festa de Todos os Santos na comunidade quilombola de Jurussaca
}

\section{The litany and All Saints' Festival in a Marron community at Jurussaca}

\author{
Jair Francisco Cecim da Silva*
}

\begin{abstract}
Resumo: Neste artigo, que é um recorte da tese de doutoramento, o propósito é analisar a ladainha entoada por ocasião da festa de Todos os Santos, principal e tradicional manifestação cultural religiosa realizada na comunidade quilombola de Jurussaca, Tracuateua-Pará, ladainha esta que acontece no sábado à noite durante a festa dançante, e marca o ponto alto da festividade. Metodologicamente, o presente estudo se apoiará em Bonvini (2006) e Calvet (2011), que pesquisam, entre outras questôes, a tradição oral em comunidades tradicionais. A pesquisa aponta que a ladainha entoada em Jurussaca apresenta uma fidedignidade impressionante com o texto original em latim, apesar de ser transmitida exclusivamente por via oral, mostrando a força da tradição oral em comunidades tradicionais como Jurussaca.
\end{abstract}

Palavras-chave: Tradição oral. Ladainha. Festa de Todos os Santos. Comunidade quilombola de Jurussaca.

Abstract: In this article, which is a clipping of the doctoral thesis, the proposal is to analyze the litany sung in the occasion of All Saint's Festival, main and traditional cultural-religious manifestation performed in the Marron Community at Jurussaca, Tracuateua-Pará, litany which happens in the Saturday night during the festival, and marks the highest point in the festivity. Methodologically, the present study will be based on Bonvini (2006) and Calvet (2011), who research, among other subjects, the oral tradition in traditional communities. The search shows that the litany sung in Jurussaca presents impressive reliability to the original text in Latin. However, it is exclusively shared orally, showing oral tradition's strength in traditional communities as Jurussaca.

Keyword: Oral tradition. Litany. All Saints' festival. Marron Community of Jurussaca.

\section{Introdução}

O propósito neste artigo é analisar a ladainha, que é entoada na festa de Todos os Santos, a principal e tradicional manifestação cultural religiosa da comunidade quilombola de Jurussaca, Tracuateua-Pará, e marca o ponto alto da festividade. Pretende-se averiguar como os cantadores entoam essa ladainha na festa: apenas balbuciam os sons que lhes foram transmitidos, cantam levando em consideração a língua original, que é o latim, ou cantam essa ladainha em português?

Essa festa teve início a partir de uma promessa feita por um morador, o qual prometeu que, se os homens náo fossem para guerra ou se fossem para guerra e voltassem vivos, faria uma festa em homenagem a todos os santos, dos quais era devoto. 
A metodologia utilizada para a coleta de dados tomou como base a pesquisa de campo, na qual foram entrevistados moradores e moradoras anciãos (âs) da comunidade, em ambientes os mais naturais possíveis destes colaboradores, como por exemplo suas casas, locais de trabalho etc. $\mathrm{O}$ instrumento utilizado na pesquisa foi a entrevista semiestruturada por meio de recursos de áudio e vídeo. Em seguida, os dados foram transcritos utilizando-se da chave de transcrição do projeto Vertentes, "[...] sistema de pontuaçáo canônico na transcriçáo do texto, o que implica a abstençáo dos registros de pausas que não tivessem uma função sintática. [...]" (Lucchesi - coordenador). Já para a análise dos dados, apoiar-se-á em Bonvini, (2006) e Calvet (2011), que pesquisam, entre outras questôes, a tradição oral em comunidades tradicionais.

Vansina (2010, p. 158, grifo do autor) define tradição oral "[...] como um testemunho transmitido oralmente de uma geração a outra, e suas características particulares são verbalismo e sua maneira de transmissão [...]" que a diferem da tradição escrita, apesar de concordar com a ideia de que definir tradição oral é bastante complexo e "[...] não é fácil encontrar uma definição [...] que dê conta de todos os seus aspectos [...]" (Vansina, 2010, p. 158). Essa complexidade se espelha na possibilidade de alteração do texto oral, o qual o autor pode corrigir, refazer, interromper, ou seja, o documento oral pode ser alterado a qualquer momento da interaçáo, diferente do texto escrito. (Vansina, 2010).

$\mathrm{O}$ artigo se compóe das seguintes seçóes: a primeira apresenta resumidamente os diversos aspectos relacionados à comunidade de Jurussaca, como a localização, a constituição (origem e formação), denominação, manifestaçóes culturais, o processo de reconhecimento de Jurussaca como remanescente de quilombo e a titulação da terra. A segunda trata da festa de Todos os Santos, a fim de localizar o leitor quanto às características dessa festivid $\neg$ ade em Jurussaca para, após, tratar especificamente da ladainha entoada nessa festa, que, como se verá, apresenta características de uma língua de cerimônia transmitida estritamente por via oral. Finalmente, apresentar-se-ão as conclusóes e as referências bibliográficas.

\section{A comunidade quilombola de Jurussaca e seus aspectos sócio-histórico-culturais.}

A comunidade quilombola de Jurussaca fica localizada na zona rural do município de Tracuateua, a aproximadamente $10 \mathrm{~km}$ da sede, na microrregião bragantina, mesorregião do nordeste do Estado do Pará, norte do Brasil.

Tracuateua é um topônimo de origem Tupi: tracuá (formiga grande) (Cunha, 1998, p.295) e teua (terra abundante). A cidade de Tracuateua, que, até 1994, era distrito do município de Bragança, cidade histórica que, em 2013, completou 400 anos, foi constituída a partir da construçáo da Estrada de Ferro Belém-Bragança, que foi iniciada no dia 10 de junho de 1884 e inaugurada, em sua totalidade, em 1908. Foram construídos 229 quilômetros do eixo principal, que ligava os municípios de Belém e Bragança. O principal objetivo da construção da estrada de ferro foi fomentar "[...] o desenvolvimento de núcleos agrícolas no estado do Pará, no período de expansão da atividade gomífera" (Leandro, Silva, 2012, p. 144). 
A população de Jurussaca oscilava (IBGE, 2010) entre 500 a 600 pessoas (Petter, Oliveira, 2011a), equivalendo a aproximadamente 85 a 90 famílias. Uma característica, em Jurussaca, é o predomínio do sobrenome Araújo, de origem galego-portuguesa, no nome das pessoas (Almeida D., 2010). A principal atividade econômica de Jurussaca é a agricultura, atividade de subsistência, predominando o plantio da mandioca para a produção de farinha e do feijão.

Há três versões com relação à origem e formação da comunidade de Jurussaca: a primeira versão é de que Jurussaca teria sido estabelecida por quatro africanos escravizados, que, fugidos de fazendas de cana de açúcar do Estado do Maranhão, se instalaram na região com o objetivo de se esconder de seus perseguidores.

DOC2: E vieram fugidos de onde?

INF: Foi as pessoas da... da... dos... dos pessoal que... que chegaram no Maranháo

de lá esses homem partiram pra cá.

DOC2: Vieram pra cá?...

DOC1: Vieram do Maranhão.

INF: É.

DOC2: ...Fugindo?

INF: É.

DOC2: Vieram fugindo do Maranhão.

INF: É... é...pessoas que... desses o... dessa companhia que veio p'o Maranhão, e do

Maranhão esses home se escaparam pra cá ... (Araújo, Valdeci, entrevista pessoal, 2011).

Outra versão dá conta de que três negros escravizados vieram fugidos do Maranhão e um de Minas Gerais.

INF: ...não... mas o meu... meu bisavô era escravo.

DOC 1: E veio de onde?

INF: Do... de Minas Gerá.

DOC 1: De Minas?

INF: Hum.

INF: Chamavam canguçu prá eles. Se mudaro muita gente... ININT... ele era de Minas

Gerá o meu bisavô... (Araújo, Vicência, entrevista pessoal, 2011).

Há uma terceira versão sobre a origem e formação da comunidade (Nascimento, Dantas, Luz, 2008, p. 24): africanos escravizados que trabalhavam nas lavouras de fazendas de Bragança-PA, fugindo do cativeiro ou, mesmo depois da abolição, temendo serem, de novo, escravizados, evadiram-se em direção à região de Jurussaca, até então pertencente ao território bragantino.

A versão de que os negros provinham da região bragantina tem respaldo nas pesquisas de Bezerra Neto (2001), que afirma que, ao observar o número de escravizados que viviam na região, ou seja, sua distribuição demográfica, “[...] a área em torno de Bragança reunia o maior número de cativos, ou seja, 482 sujeitos que perfaziam 7\% da sua população de 6.847 moradores [...]” (Bezerra Neto, 2001, p. 101).

O grande número de negros escravizados, na região bragantina, deveu-se à diversidade de produtos agrícolas cultivados na região, entre os quais o café, a cana de açúcar e a mandioca, além da pecuária, com a presença de algumas fazendas de criação de gado na região, que demandava uma quantidade considerável de mão de obra escravizada (Bezerra Neto, 2001). 
O período em que os povos africanos escravizados foram trazidos à força para trabalharem nas fazendas do Maranhão e do Pará se deu no século XVIII. Até o século XVII, a regiáo norte do Brasil permaneceu intocada e desconhecida por parte dos colonizadores europeus. Era povoada por indígenas, com o predomínio dos índios Tupinambás ou Tupis. Os africanos escravizados trazidos para o Grão-Pará e que, possivelmente, podem ter participado da formaçáo do povo da comunidade de Jurussaca pertencem a três grupos linguísticos: (i) os falantes de línguas bantas, (ii) os falantes de línguas cuá e (iii) os falantes de línguas defóide (Figueiredo, Oliveira, 2013, p. 112).

(i) Linguas Bantas - os escravos que falavam essas línguas foram trazidos da costa oeste africana das atuais repúblicas do Congo, República Democrática do Congo, Angola, e mais tarde, da costa leste africana, mais propriamente de Moçambique. Compreendem as línguas faladas pelo maior número de cativos (Bonvini, 2008, p.30). Em Angola, três línguas bantas muito faladas são umbundu, quimbundu e quicongo (hoje, três das quatro "línguas nacionais" do país).

(ii) Linguas Cuá (subgrupo gbe) - os negros que falavam essas línguas eram oriundos do chamado "Ciclo da Costa da Mina" e conhecidos ainda como "sudaneses". Atualmente esta área linguística compreende os países africanos de Gana, Togo, Benin e Nigéria. Três línguas muito citadas são gbe, eve e fon. Línguas desse grupo são designadas no Brasil pelo termo jeje (Bonvini, 2008, p. 30).

(iii) Linguas Defóide - os negros desse grupo atestavam diferentes falares iorubás e são conhecidos no Brasil pelo termo nagô-queto (Bonvini, 2008, p. 30). Eram provenientes da Nigéria (Figueiredo, Oliveira, 2013, p.112).

Em relação ao nome da comunidade, Jurussaca foi primeiramente chamada "Rocinha".

DOC 1: Dona Vicência, a senhora nasceu no Jurussaca?

INF: Na... INTERRUP

DOC 1: ININT

INF: Nasci, quer dizer que é... era no Jurussaca, mas se chamavo casa Rocinha

DOC 1: Casa Rocinha?

INF: Hum.

INF: [Dia] era...tinha placa grande... assim... que meu tio fez... assim na parede... era

Casa Rocinha... (Araújo, Vicência, entrevista pessoal, 2011).

O depoimento acima demonstra que Rocinha era a denominação de uma casa - a presença de "uma placa grande" possibilitou deduzir que casa Rocinha seria um comércio, uma mercearia - que deu nome à comunidade. Diferentemente, os dois outros depoimentos, abaixo, descrevem a Rocinha como um espaço geográfico que denominava a comunidade, e um dos primeiros locais a ser explorados.

INF: Porque os primeiros habitantes que moraro aqui foram as pessoas que vieram, eh...dum tempo foragido, assim... do tempo daquela guerra, né, que teve... eles vieram e se colocaram, foram três pessoa... se colocaram um lá na beira do rio Jurussaca lá que o nome dele era Raimundo Jurussaca... aí se colocaram outro aqui... que era o... o Benedito Ludovino... aí tem outro que morava na rocinha... na rocinha é um local que tem umas mangueira lá aí é pra onde a gente só trabalha, aí todo mundo botô o apelido de rocinha pra lá... aí é a terra firme pra lá... aí ficou, eh, essas três pessoa que começaram a fazer a família aqui. (Araújo, Valdeci, entrevista pessoal, 2011).

INF1: Não... sempre eles falava numas velha que morava na rocinha... não sei pra onde... pra cá... mas ele não falava o que era... que era o quilombo, né... (Araújo, Umbelina, entrevista pessoal, 2011). 
A ladainha e a Festa de Todos os Santos na comunidade quilombola...

Com o passar dos anos, a comunidade passou a se chamar Jurussaca (Nascimento, Dantas, Luz, 2008, p. 24). Não foi possível obter informaçóes de como e quando essa mudança aconteceu.

O significado do topônimo Jurussaca, assim como a mudança de nome da Comunidade, também apresenta duas versóes: uma delas diz respeito a uma possível tradição, em que, quando uma pessoa prejudicava a outra fazendo algum mal a ela e arrependida pedia-lhe perdão, a causadora do mal, para se desculpar, deveria enfiar a cabeça numa saca, prometendo jurar que não a prejudicaria mais, ou seja, deveria jurar na saca, resultando daí o nome Jurussaca (Nascimento, Dantas, Luz, 2008, p. 24). Outra versão é de que o topônimo Jurussaca seria o sobrenome de um de seus fundadores - um dos quatro escravizados fugidos. Vale ressaltar que não há informações precisas sobre essas versóes.

As manifestações culturais mais significativas da comunidade de Jurussaca dizem respeito a atividades de caráter religioso de tradição católica, que são três: a festa de Coroação de Nossa Senhora no mês de maio, o Círio de Santa Maria no mês de setembro e a mais tradicional da Comunidade, a festa de todos os Santos, no mês de outubro. A população de Jurussaca participa ainda de duas outras festividades que acontecem na cidade de Tracuateua: a festa em homenagem a São Sebastião e São Benedito com a tradicional Marujada, que ocorre no mês de janeiro, diferentemente da de BragançaPA, que tradicionalmente ocorre no final de dezembro, e o Círio de Nossa Senhora de Nazaré, no segundo domingo de agosto.

O reconhecimento e titulação como remanescente de quilombo das comunidades quilombolas se reflete na territorialidade desses grupos, ou seja, na ocupação e uso da terra, sobre o qual chama-se a atenção para um fato importante que caracteriza as comunidades quilombolas de modo geral:

[a] prática do sistema de uso comum de suas terras, concebidas por elas como um espaço coletivo e indivisível que é ocupado e explorado por meio de regras consensuais aos diversos grupos familiares que compóem as comunidades, cujas relaçóes são orientadas pela solidariedade e ajuda mútua (Pinto, 2011, p. 82).

Ou seja, sistema de uso comum das terras obedece a uma sazonalidade das práticas, tanto agrícolas quanto extrativistas, "[...] caracterizando diferentes formas de uso e ocupação dos elementos essenciais ao ecossistema [...]” (O’dwyer, 2002, p. 18).

Após muitos esforços, a comunidade foi reconhecida como remanescente de quilombo, quando recebeu o título de reconhecimento coletivo, com base na Lei Estadual No 6.165, de dois de dezembro de 1998, que dispóe sobre a legitimação de terras dos remanescentes das comunidades dos quilombos. Foi delimitada uma área de 200.9875 ha. $\mathrm{O}$ título de reconhecimento de domínio coletivo da terra foi entregue à comunidade no dia 14 de setembro de 2002.

DOC 1: [...] deixa eu te perguntar uma co... perguntar uma coisa pra vocês. Quando foi certificada essa terra que com... é... como... é... comunidade quilombola? Quando foi? INF 1 : Que ano, né?

DOC 1: Que ano? Mil novecentos e?

INF 1 : Diz aí, Antônia.

INF 2: [Não] ...esqueci... 
INF 1: Eu sei que foi naquele dia, tu lembra? No dia que foi o título da terra que eu puxei aquela camisa do [Redicicure]. E eu disse: "Olha, Antônia, catorze de setembro..." De quê? Dia que foi, Antônia? Tá lá em casa a camisa. \{risos\} [A história da camisa...]

INF 1: eu sei que... no dia da entrega do título foi uma coisa muito bonito. (Araújo, Antonia, entrevista pessoal, 2011).

O panorama etnográfico de Jurussaca apresentado até o momento, apontando os diversos aspectos relacionados à comunidade, revelou que os moradores apontam diversas versóes quanto à localizaçáo, à constituição (origem e formação) e à denominação de Jurussaca. Essas diversas versóes são frequentes em comunidades reconhecidamente tradicionais, como Jurussaca, haja vista que essas comunidades apresentam, como característica principal da sua prática social e linguística, a comunicação oral, prática linguística bastante tradicional em comunidades quilombolas, principalmente, de moradores mais velhos, que são os "[...] representantes da memória coletiva da comunidade" (Oliveira E., 2006, p. 33).

Em comunidades que têm como prática linguística e social a transmissão oral, “[...] a forma de armazenagem de informaçóes é a memória [...]” (Oliveira E., 2006, p. 34). A memória coletiva é concebida como uma categoria que tem base histórica e é representada por "[...] determinados fatos, acontecimentos, situaçóes [...]" (Montenegro, 1994, p. 18 apud Oliveira E., 2006, p. 33; nota 7), que sáo reelaborados, constantemente, tanto pelo grupo quanto pelo indivíduo, podendo suscitar que se criem e recriem essas diversas versóes, que são frequentes na transmissão das informaçóes históricas da comunidade como visto acima.

Após apresentar um resumo dos aspectos culturais históricos e sociais da comunidade quilombola de Jurussaca, a seguir vão ser abordadas questóes relacionadas ao objetivo proposto neste artigo, que é analisar a ladainha entoada na festa de Todos os Santos.

\section{A festa de todos os santos}

A festa de Todos os Santos, conforme a tradição da igreja católica apostólica romana, homenageia, como o próprio termo sugere, todos os santos e santas de Deus. Essa festa, que é uma manifestação religiosa muito tradicional de Jurussaca, e na qual a ladainha é entoada, teve início devido a uma promessa feita pelo senhor Benedito Antônio de Araújo, 'seu Bibiano', morador da comunidade:

INF 2: [...] essa festa surgiu foi no tempo da guerra. Que um senhor daqui, um senhor... é... Bibiano, que morava...um morador daqui da comunidade... (Araújo, Antonia, entrevista pessoal, 2011).

INF 2: Ah era... era o Bene \{a informante ri\}... era daí mesmo do... do...

INF 1: Como era o nome do Benedito?

INF2: Era Benedito parece que era Benedito Fernando Araújo (Araújo, Fausta e Araújo, Manoel, entrevista pessoal, 2011).

O governo, através da Força Expedicionária Brasileira (FEB), convocou todos os homens para a guerra - os depoimentos relacionados a que guerra os homens foram convocados apresentam várias versóes: uns apontam que a convocaçáo ocorreu por ocasião da 2a Guerra Mundial, outros, por ocasião da guerra do Paraguai: 
INF: Não, essa festa... a gente tem uma revista que... ela já tem uns duzentos anos que tá na revista, mas acho que ela é [an]....mais...que ela começou no tempo da... da guerra... da... né, da Itália né. (Araújo, Antonia, entrevista pessoal, 2011).

INF 2: ...Por que eles contavam assim... não teve aquela guerra lá?

INF 1: É

INF2: A guerra do Paraguai num foi? que ali naquele tempo ia buscar, né, uai, não foi? Como foi? e levavam mesmo eles ..então fugiam desse tempo eles eram tudo novos, né, jovem.

INF 3: Foi essa do Paraguai... que era a cobra fumando, né?

INF 2: Não, não, a cobra fumando já foi depois (Araújo, Fausta e Araújo, Manoel, entrevista pessoal, 2011).

Temendo que todos os homens da comunidade fossem para a guerra, o senhor Benedito prometeu que, caso os convocados não fossem para o front, inclusive ele, realizaria uma grande festa em homenagem a todos os santos, evento religioso católico que acontece no dia primeiro de novembro, véspera do dia de finados. Uma semana antes de os homens irem para a batalha, a guerra acabou; logo, a "promessa" foi cumprida. $\mathrm{O}$ senhor Benedito Antônio de Araújo, então, realizou a festa e a presidiu até a sua morte.

INF 2: [...] O Brasil teve que mandar soldados pra lá, pra guerra. Quando chegaram lá, e... aí, ele... a... hum... a mãe dele, que ficou aqui, aí falou que tomara que quando ele chegasse lá já tivesse acabada, né, o...o...acabado a guerra, ou então ele voltasse vivo. Entáo, ela ia mandá fazê a... uma festa de todos os santo. Juntava os santo, agora, aí a gente não sabe também... (Araújo, Antonia, entrevista pessoal, 2011).

INF2: Pois é... se todos os santos fizesse com que acabasse a guerra e eles não fossem pra guerra... que eles iam festejar todo ano... todos os santos, né? e...

INF2: ...E iam buscar os santos e iam festejar mandavam rezar e festejar todos os santos e como eles não foram eles fizeram... cumpriram com a promessa INTERRUP (Araújo, Fausta e Araújo, Manoel, entrevista pessoal, 2011).

A festa tem a duração de quatro a cinco dias e se inicia com uma peregrinação, percorrendo várias comunidades no entorno de Jurussaca. A procissáo começa em Jurussaca encabeçada por uma imagem de São Benedito, considerado o padroeiro dos negros escravizados na tradição cristã católica. Na peregrinação, o santo "visita" as casas que fazem parte do trajeto e, se, em cada casa visitada, houver uma imagem de santo, independente de qual seja, esta pode ser introduzida na romaria até o retorno a Jurussaca, onde ocorre a festa.

Na chegada a Jurussaca, depois de um dia inteiro de caminhada, os "santos visitam" as casas dos moradores de Jurussaca. Um aspecto interessante é que todas as pessoas que carregam as imagens têm que envolvê-las em um pano como se as estivessem protegendo igual a uma criança de colo. Todas as imagens são reunidas e acomodadas em uma mesa ("altar"), construída de alvenaria, devidamente coberta por um tecido, no barracão onde ocorre a festa dançante animada por uma aparelhagem de som. A mesa em que as imagens são acomodadas fica de frente para a porta de entrada do saláo de festa num espaço de $1 \mathrm{~m} 2$, cercado, logo, "protegido", mas náo escondido, para que as pessoas, mesmo no momento da festa dançante, possam homenageá-las.

A festa dançante, que acontece no sábado à noite, é um dos pontos altos do período festivo, pois é durante a dança que acontecem as homenagens a todos os santos. $\mathrm{O}$ ritual religioso acontece da seguinte forma: num determinado momento da festa, 
a aparelhagem de som para de tocar e todas as pessoas que estiverem no ambiente se aproximam dos santos para que seja entoada a ladainha.

A festa de todos os santos tornou-se para a comunidade um evento significativo, em que a comunicaçáo oral coletiva, como afirma Bonvini (2006, p. 5), ocorre em um lugar e momento privilegiadíssimo, ritualmente definido: "[...] à noite, ou durante a estaçáo da seca, ou ainda no interior da aldeia e náo no exterior [...]". A festa, por exemplo, acontece num local bem demarcado, que é a sede de festas da comunidade, e num momento que marca a história da comunidade e, por isto, muito aguardado, o momento de se cumprir a promessa feita por "seu" Bibiano.

A palavra festa é conceituada como um elemento constantemente presente na vida das pessoas e demanda uma ação tanto individual quanto coletiva (Perez, 2012 apud Pena, 2014), "[...] que se dá num tempo e lugar definidos e especiais, implicando a concentração de afetos e emoçôes em torno de um objeto que é celebrado e comemorado [...]" (Guarinello, 2001, p. 972 apud Pena, 2014, p. 19).

A festa " $[. .$.$] pode pertencer aos registros religioso e profano, não estando, porém,$ vinculada ao sagrado. Sem ter necessariamente finalidade religiosa [...]" (Aranha Silva, 2007 , p. 27). No caso específico de Jurussaca, a palavra festa apresenta uma conotaçáo diferente da apontada por Aranha Silva (2007, p.27): a festa de todos os santos pertence aos registros religioso e profano concomitantemente, e há um vínculo entre o religioso e o profano, vínculo este que ocorre de modo táo imbricado que estes dois espaços em Jurussaca se confundem, ou seja, náo se sabe quando começa um e termina outro. Essa imbricação, que pode supor certa confusão, é bastante simbólica para os moradores de Jurussaca, uma vez que, em conversa informal com o presidente da associaçáo (comunicação pessoal), ele diz: "se a festa é deles (de todos os santos) não tem razão de ficarem de fora", por isso as imagens (registro religioso) ficam no local da festa (registro profano de acordo com a tradição cristã).

Os santos presentes no local de festas têm um significado que reflete o próprio comportamento cotidiano da comunidade. Conforme uma moradora de Jurussaca (comunicação pessoal), colocar os santos em um local que não seja o da festa provoca certa desorganizaçáo, desordem no tempo e nas relaçóes sociais da comunidade: as lavouras náo vingam, os animais morrem, as pessoas adoecem ou se desentendem facilmente sem uma explicação plausível. Nesse sentido, "[...] o ritual faz sentido para os que dele participam, marcam épocas e representam determinadas escolhas e tempos sociais [...]" (Aranha Silva, 2007, p. 27).

Pelo fato de as imagens permanecerem no local da festa, como citado acima, a ladainha também é entoada nesse local.

\section{A ladainha e a tradiçáo oral}

A palavra ladainha, do grego litanéia, derivada da palavra grega lite, significa súplica (Souza, M., 2011, p. 84). A ladainha, que, segundo a tradição católica, faz parte de um rito, é utilizada em cerimônias religiosas. "A palavra cerimonial sempre esteve associada à palavra ritual [...]” (Aranha Silva, 2007, p. 26), e a palavra ritual, derivada 
da palavra "rito", "[...] remete [...] à ordem do cosmo, à ordem das relaçôes entre os deuses e os homens, à ordem dos homens entre si” (Benveniste, 2002, p. 17), ou seja, a cerimônia, o rito em que a ladainha é entoada, tem a função de estabelecer ligação e harmonização entre os homens e Deus por intercessão de Maria, dos santos, além de permitir a reunião, a solidariedade, a comunhão dos homens entre si.

Silva, G. (2013: manuscrito), que transcreveu a ladainha entoada em Jurussaca, atesta que a ladainha de Nossa Senhora é o texto entoado na festa de Todos os Santos.

Chama-se a atençáo para o fato de que a tradiçáo de se homenagear Maria, a máe de Jesus, através de cantos e súplicas, começou, por volta do século XVI, na cidade de Loreto (Itália) (Basadonna, Cantarelli, 2000, p. 19). Por ter se originado na cidade de Loreto, a ladainha é também chamada de lauretana (Vaz, 2005, p. 13). A ladainha chegou ao Brasil através dos missionários jesuítas no período da colonização portuguesa.

A ladainha cantada em Jurussaca foi coletada a partir de um corpus em vídeo registrado em um momento em que fora entoada na capela da comunidade fora do período da festa de Todos os Santos. A transcrição foi feita por Silva, G. (2013: manuscrito) com base na chave de transcriçáo do projeto Norma Urbana Culta (NURC).

Após fazer a transcrição da ladainha entoada em Jurussaca, Silva, G. (2013: manuscrito) comparou-a com as versóes em latim e em português. Vale frisar que a ladainha de Nossa Senhora, na versão em português, é cantada até hoje em diversas cerimônias católicas.

Abaixo, a ladainha de Nossa Senhora aparece em três versóes: a versão que é entoada em Jurussaca, a versão escrita em latim e a traduçáo em português.

\section{Quadro 1 - Ladainha de Nossa Senhora}

\begin{tabular}{|c|c|c|}
\hline $\begin{array}{l}\text { LADAINHA CANTADA } \\
\text { EM JURUSSACA }\end{array}$ & LADAINHA EM LATIM & $\begin{array}{l}\text { LADAINHA EM } \\
\text { PORTUGUÊS }\end{array}$ \\
\hline \multicolumn{3}{|l|}{ Ky: ele:son } \\
\hline \multicolumn{3}{|l|}{ Cres:ton ele:son audi:nos } \\
\hline \multicolumn{3}{|l|}{ ININT } \\
\hline \multicolumn{3}{|l|}{ Cali De:us, mi:sare: no:bes } \\
\hline \multicolumn{3}{|l|}{ Creton: mae de De:us } \\
\hline \multicolumn{3}{|l|}{ ININT mi:sare: no:bes } \\
\hline Santa Treni:ta o:rai pro no:bes & $\begin{array}{l}\text { Sancta Trinitas, unus } \\
\text { Deus, miserere nobis }\end{array}$ & $\begin{array}{l}\text { Santíssima Trindade, } \\
\text { que sois um só Deus, } \\
\text { tende piedade de nós }\end{array}$ \\
\hline Santa Mare:a & Sancta Maria & Santa Maria \\
\hline Santa de Genitre: & Sancta Dei Genitrix & Santa Mãe de Deus \\
\hline $\begin{array}{c}\text { Santa de Vi:rgeno: } \\
\text { o:ra pro no:bes }\end{array}$ & $\begin{array}{c}\text { Sancta Virgo virginum, } \\
\text { ora pro nobis }\end{array}$ & $\begin{array}{c}\text { Santa virgem das virgens, } \\
\text { rogai por nós }\end{array}$ \\
\hline Mande Criste o:ra pro no:bi & Mater Christi, ora pro nobis & $\begin{array}{c}\text { Mãe de Jesus Cristo, } \\
\text { rogai por nós }\end{array}$ \\
\hline ININT & ININT & ININT \\
\hline Mater pore:cima & Mater puríssima & Mãe puríssima \\
\hline
\end{tabular}




\begin{tabular}{|c|c|c|}
\hline $\begin{array}{l}\text { Mater caste:ssima } \\
\text { o:ra pro no:bes }\end{array}$ & Mater castissima, ora pro nobis & Mãe castíssima, rogai por nós \\
\hline Mater invio:lata o:rai por no:be & Mater inviolata, ora pro nobis & Mãe imaculada, rogai por nós \\
\hline Mater temelal:ta & Mater intemerata & Mãe intacta \\
\hline Mater ama:bele: & Mater amabilis & Mãe amável \\
\hline $\begin{array}{c}\text { Mater adimera:bele } \\
\text { o:ra pro no:bes } \\
\end{array}$ & $\begin{array}{c}\text { Mater admirabilis, } \\
\text { ora pro nobis }\end{array}$ & Mãe admirável, rogai por nós \\
\hline Mater criato:rio o:rai pro no:bi & Mater Creatoris, ora pro nobis & Mãe do criador, rogai por nós \\
\hline Mater Salvato:rio: & Mater Salvatoris & Mãe do salvador \\
\hline Virga Prodenti:ssema: & Virgo prudentíssima & Virgem prudentíssima \\
\hline $\begin{array}{c}\text { Virga Veneran:da } \\
\text { o:ra pro no:bes }\end{array}$ & Virgo veneranda, ora pro nobis & $\begin{array}{l}\text { Virgem venerável, } \\
\text { rogai por nós }\end{array}$ \\
\hline $\begin{array}{l}\text { Virga amedica:na } \\
\text { o:rai por no:bes }\end{array}$ & $\begin{array}{l}\text { Virgo praedicanda, } \\
\text { ora pro nobis }\end{array}$ & Virgem louvável, rogai por nós \\
\hline Virga opon:te: & Virgo potens & Virgem poderosa \\
\hline Virga ocleme: & Virgo Clemens & Virgem benigna \\
\hline Virga fideli o:lai pro no:bes & Virgo fidelis, ora pro nobis & Virgem fiel, rogai por nós \\
\hline $\begin{array}{l}\text { Spiquirum lejusti:ce: } \\
\text { o:lai pro no:bes }\end{array}$ & $\begin{array}{l}\text { Speculum justitiae, } \\
\text { ora pro nobis }\end{array}$ & $\begin{array}{l}\text { Espelho de justiça, } \\
\text { rogai por nós }\end{array}$ \\
\hline Virga de sapira:cien & Sedes sapientiae & Sede da sabedoria \\
\hline Causa nostra etrelati:cie & Causa nostra elaetitiae & Causa de nossa alegria \\
\hline $\begin{array}{l}\text { Vaso esperetoa:le } \\
\text { vo:la pro no:bes } \\
\end{array}$ & Vas spirituale, ora pro nobis & Vaso espiritual, rogai por nós \\
\hline Vas honora:bies o:ra pro no:be & Vas honorabile, ora pro nobis & Vaso honorifico, rogai por nós \\
\hline Insigne davocio:NE & Vas insigne devotionis & Vaso insigne de devoção \\
\hline Rosa me:stica: & Rosa mystica & Rosa mística \\
\hline $\begin{array}{c}\text { Tor:re Dave:stica } \\
\text { zo:la pro no:be }\end{array}$ & Turris Davidica, ora pro nobis & Torre de Davi, rogai por nós \\
\hline Tor:re zebo:nhe: o:rai pro no:be & Turris eburnea, ora pro nobis & Torre de marfim, rogai por nós \\
\hline Domenus a:rea: & Domus aurea & Casa de ouro \\
\hline Fideris arca: & Foederis arca, & Arca da aliança \\
\hline Jaluloce:li o:ra pro no:be & Januacaeli, ora pro nobis & Porta do céu, rogai por nós \\
\hline $\begin{array}{l}\text { Etrela Matute:na } \\
\text { o:rai pro no:be }\end{array}$ & Stella matutina, ora pro nobis & Estrela da manhã, rogai por nós \\
\hline Salus infermo:rio: & Salus infirmorum & Saúde dos enfermos \\
\hline Refogio precato:rio: & Refugium peccatorum & Refúgio dos pecadores \\
\hline $\begin{array}{c}\text { Consolatre repleto:rio } \\
\text { o:rai pro no:bes }\end{array}$ & $\begin{array}{c}\text { Consolatri xafflictorum, } \\
\text { ora pro nobis }\end{array}$ & $\begin{array}{l}\text { Consoladora dos aflitos, } \\
\text { rogai por nós }\end{array}$ \\
\hline $\begin{array}{l}\text { Xilium christinum: } \\
\text { o:rai pro no:be }\end{array}$ & $\begin{array}{l}\text { Auxilium christianorum, } \\
\text { ora pro nobis }\end{array}$ & $\begin{array}{l}\text { Auxílio dos cristãos, } \\
\text { rogai por nós }\end{array}$ \\
\hline ININT ange:lou: & ININT angeloru & ININT anjos \\
\hline Regina plateioca:io: & Regina patriarcharum & Rainha dos patriarcas \\
\hline $\begin{array}{l}\text { Regina professo:ro } \\
\text { zo:la pro no:be }\end{array}$ & $\begin{array}{l}\text { Regina prophetarum, } \\
\text { ora pro nobis }\end{array}$ & $\begin{array}{l}\text { Rainha dos profetas, } \\
\text { rogai por nós }\end{array}$ \\
\hline
\end{tabular}


A ladainha e a Festa de Todos os Santos na comunidade quilombola...

\begin{tabular}{ccc}
\hline $\begin{array}{c}\text { Regina apostelo:rion: } \\
\text { o:rai pro no:be }\end{array}$ & $\begin{array}{c}\text { Regina apostolorum, } \\
\text { ora pro nobis }\end{array}$ & $\begin{array}{c}\text { Rainha dos apóstolos, } \\
\text { rogai por nós }\end{array}$ \\
\hline Regina simela:be: & Regina sinelabe & \\
\hline Regina conce:peto: & Regina concepta & \\
\hline $\begin{array}{c}\text { Regina sacratíssimo } \\
\text { rosa:rio o:ra pro no:be }\end{array}$ & $\begin{array}{c}\text { Regina sacratissimi } \\
\text { Rosarii, ora pro nobis }\end{array}$ & $\begin{array}{c}\text { Rainha do santo rosário, } \\
\text { rogai por nós }\end{array}$ \\
\hline Regina pla:ci:s o:rai pro no:be & Regina pacis, ora pro nobis & Rainha da Paz \\
\hline $\begin{array}{c}\text { Angelus De:o: esquitale } \\
\text { specateno:bede }\end{array}$ & $\begin{array}{c}\text { Agnus Dei, quitolli speccata } \\
\text { mundi, parcenobis, }\end{array}$ & $\begin{array}{c}\text { Cordeiro de Deus, que tirais o } \\
\text { pecado do mundo, perdoai-nos }\end{array}$ \\
\hline Esquitale speca teno:bede & Quitoll ispeccata mundi & Que tirais o pecado do mundo \\
\hline Audi-no De:i & Exaudi-nos, & Ouvi-nos \\
\hline Audi-no Do:i & Exaudi-nos, & Ouvi-nos
\end{tabular}

Fonte: (Silva, G., 2013, manuscrito)

Embora encontrada na versão escrita, a ladainha entoada em Jurussaca, como em muitas outras comunidades, é transmitida estritamente por via oral. Geralmente, o cantador principal transmite a seus filhos ou a outros moradores mais jovens, que é o que está ocorrendo em Jurussaca, os quais, de geração em geração, mantêm a tradição demonstrando a força da tradição oral (Oliveira, E., 2006, p.33).

Para os ouvidos mais desatentos, leigos, como os dos que náo participam diretamente da ladainha, os de fora, tem-se a impressáo, e até uma atitude "errada", de que os cantadores da ladainha apenas balbuciam os sons e que eles mesmos não entendem o que estão cantando.

A transcrição da ladainha feita por Silva, G. (2013) e a análise dos dados mostrou o contrário, pois o texto é inteligível, e o que mais impressionou é que praticamente toda a extensão do texto é cantada em uma variante do latim preservada até os dias atuais, alternando-se em alguns momentos com palavras em português, embora, muito provavelmente, os "cantadores"/rezadores não tenham noção do que estejam proferindo, pois eles não aprenderam "latim" ou foram introduzidos a nenhum ensinamento formal para reter esta "língua".

A composição da ladainha cantada em Jurussaca reflete um estilo tipicamente oral, carregado de ritmo, de repetiçóes sucessivas de frases, de paralelismos, refrãos, que fazem parte da trama do texto e facilitam a memorização do texto, contribuindo assim para melhor evocar o conteúdo do texto (Bonvini, 2006), e, por conseguinte, manter a tradição, que constitui a memória coletiva da comunidade.

Calvet (2011, p. 22), analisando diversas versóes de textos orais transmitidos por muitas geraçóes, chama a atenção que "[...] todos os contadores insistem no fato de que eles transmitem o que lhes foi transmitido [...], que eles não inventam nada [...]". A fidelidade ao texto transmitido oralmente está diretamente ligada a algumas características deste texto: uma delas, e talvez a principal, diz respeito à forma cantada na produção do texto, forma esta na qual “[...] a relação nota/sílaba impóe uma certa fixidez [...]" (Calvet, 2011, p.15), marcada por um ritmo "[...] que facilita para o contador de história a memorização e para o público a compreensão" (Houis, 1971, p. 46 apud Calvet, 2011, p.21), garantindo, assim, a fixidez definitiva de algumas destas formas e a transmissão sem variação nenhuma (Calvet, 2011, p.15). 
A ladainha em Jurussaca, por ser cantada, é transmitida quase sem nenhuma variação: corroborando essa fidelidade, alguns trechos são exatamente idênticos ao texto original encontrado na literatura escrita; outros, quando não são idênticos, são bastante convergentes; outros ainda assumem características da língua falada no dia a dia.

Vale frisar que o texto oral também apresenta variaçóes, as quais [...] não são traições de uma forma ne varietur que eles tentaram restituir. Elas se inscrevem em um certo estilo que, se facilita a memorização, responde, também, a outras funçóes, o estilo oral (Calvet, 2011, p. 22) (grifos do autor).

O estilo oral garante a liberdade de quem conta, que é muito grande, no entanto o conteúdo semântico e algumas fórmulas-chave são mantidos (Calvet, 2011, p. 15). Essa liberdade acontece mais no texto em prosa, é o caso, por exemplo, dos depoimentos referentes à origem e formação da comunidade de Jurussaca, à origem do nome (topônimo) da comunidade, etc., que apresentam versóes variadas para a mesma história, no entanto o conteúdo semântico e algumas fórmulas-chave permanecem. "[...] Essa variante individual, que pode ser estilística, pode também ser contextual, adaptada a tal evento ou a tal auditório [...]" (Calvet, 2011, p. 23).

O dado abaixo, da ladainha cantada em Jurussaca, comparado com a versão latina, apresenta um grau consideravelmente grande de fidelidade dos cantadores ao texto em latim.

\begin{tabular}{ccc}
$\begin{array}{c}\text { LADAINHA CANTADA } \\
\text { EM JURUSSACA }\end{array}$ & LADAINHA EM LATIM & $\begin{array}{c}\text { LADAINHA EM } \\
\text { PORTUGUES }\end{array}$ \\
\hline Santa Treni:ta o:rai pro no:bes & $\begin{array}{c}\text { Sancta Trinitas, unus } \\
\text { Deus, miserere nobis }\end{array}$ & $\begin{array}{c}\text { Santíssima trindade, } \\
\text { rogai por nós }\end{array}$ \\
\hline Santa Mare:a & Sancta Maria & Santa Maria \\
\hline Santa de Genitre: & Sancta Dei Genitrix & Santa Mãe de Deus \\
\hline $\begin{array}{c}\text { Santa de Vi:rgeno: } \\
\text { o:ra pro no:bes }\end{array}$ & $\begin{array}{c}\text { Sancta Virgo virginum, } \\
\text { ora pro nobis }\end{array}$ & $\begin{array}{c}\text { Santa virgem das virgens, } \\
\text { rogai por nós }\end{array}$ \\
\hline Mande Cri:ste o:ra pro no:bi & Mater Christi, ora pro nobis & $\begin{array}{c}\text { Mãe de Jesus Cristo, } \\
\text { rogai por nós }\end{array}$
\end{tabular}

Em uma única ocorrência, abaixo, os cantadores entoam somente em português, a língua falada no dia a dia dos jurussaquenses: mãe de De:us. Creton é uma variação da palavra latina Christe (Cristo).

\begin{tabular}{|c|c|c|}
\hline $\begin{array}{l}\text { LADAINHA CANTADA } \\
\text { EM JURUSSACA }\end{array}$ & LADAINHA EM LATIM & $\begin{array}{l}\text { LADAINHA EM } \\
\text { PORTUGUES }\end{array}$ \\
\hline Creton: mãe de De:us & & \\
\hline
\end{tabular}

Analisando os trechos acima, é possível afirmar que a ladainha, quase exclusivamente cantada em latim, se transformou em um fóssil linguístico, ou seja, um texto de uma língua considerada morta na modalidade oral - o latim -, que se manteve quase totalmente inalterado tanto fonética quanto graficamente, mesmo em um contexto de uso exclusivo da língua portuguesa em sua variedade vernacular. 
A ladainha e a Festa de Todos os Santos na comunidade quilombola...

Na pesquisa, observa-se que a ladainha é entoada preferencialmente por homens e transmitida por via oral seguindo uma tradição em que os mais velhos transmitem para os mais novos. Vale ressaltar que a ladainha entoada em Jurussaca apresenta, apesar de ser transmitida quase que exclusivamente por via oral, uma fidedignidade impressionante ao texto original em latim, o que mostra a força da tradição oral em comunidades tradicionais como Jurussaca.

Chamou a atenção o fato que só homens são os responsáveis pela entoação da ladainha. As outras pessoas (mulheres, crianças, etc.) são expectadores, mas essas pessoas podem participar entoando também a ladainha, mas em forma de acompanhamento, em forma de um coro responsivo. Sáo seis homens os cantadores principais da ladainha: três na frente e três atrás dispostos um atrás do outro formando duas fileiras. Os três cantadores da frente são os responsáveis por iniciar a ladainha, sendo o do meio o cantador principal quem comanda o evento.

Na ilha de Ano Bom, localizada na república da Guiné Equatorial, no continente africano, colonizada pelos portugueses no século XV, atesta-se uma cerimônia religiosa também de tradição católica como em Jurussaca, em que os responsáveis também são em número de seis homens: cinco sangitan (sacristão) e o sangitan gandji (sacristão grande) (Silveira, Agostinho, Bandeira, Freitas, Araújo, 2013, p. 27).

O cantador principal da ladainha, em Jurussaca (o sangitan gandji na ilha de Ano Bom), torna-se uma autoridade no rito, garantindo a existência e a legitimidade desse ato, embora seja um simples agricultor fora do espaço e do tempo rituais. Aranha Silva (2007, p. 28) afirma que a "[...] figura de quem conduz a solenidade ou de quem comanda as etapas previstas para aquele rito começa a aparecer como fundamental [...]", e cita Bourdieu (1998) para corroborar o poder de autoridade que o cantador principal assume no rito:

[...] O porta-voz autorizado é aquele ao qual cumpre, ou cabe, falar em nome da coletividade; é ao mesmo tempo seu privilégio e seu dever, sua função própria, em suma, sua competência (no sentido jurídico do termo) (Bourdieu, 1998, p. 101 apud Aranha Silva, 2007, p. 28).

Como porta-voz autorizado pela comunidade, o cantador principal da ladainha dá início a ela e os que estão ao seu lado acompanham. Os cantadores de fileira de trás repetem os versos cantados pelos da frente e emendam outro verso superpondo a voz dos que estão na frente. Enquanto a fileira da frente vai terminando um verso, a de trás começa outro antes que a primeira termine.

A variedade de língua que normalmente é utilizada nas ladainhas é chamada de língua litúrgica ou língua de cerimônia (Silveira, Agostinho, Bandeira, Freitas, Araújo, 2013). Essa língua de cerimônia pode diferir, em alguns casos, da variedade empregada cotidianamente pelos participantes da ladainha.

Analisando a principal manifestação religiosa da ilha de Ano Bom, Silveira, Agostinho, Bandeira, Freitas, Araújo (2013, p. 28) apontam que, apesar de os anobonenses já possuírem uma língua própria, o Fa d'ambô, nas cerimônias os anobonenses utilizam “[...] uma variedade híbrida, com muitos elementos do Fad'ambô, do português quinhentista e do moderno [...], misturados a palavras latinas e também influenciada pelo ambiente 
ecolinguístico da comunidade [...]”. Analisando a principal manifestação religiosa em Jurussaca, a festa de Todos os Santos, há semelhanças dessa manifestaçáo com a da ilha: em Jurussaca, a língua falada cotidianamente pelos jurussaquenses, o português vernacular brasileiro, não é a mesma empregada na ladainha: como visto acima, em alguns trechos da ladainha, elementos do latim, língua das cerimônias, se mesclam e se alternam com elementos do português.

No dado abaixo, em uma mesma frase, há a ocorrência de palavras tanto do latim quanto o português - orai (português) pro nobi (latim):

\begin{tabular}{ccc}
$\begin{array}{c}\text { LADAINHA CANTADA } \\
\text { EM JURUSSACA }\end{array}$ & LADAINHA EM LATIM & $\begin{array}{c}\text { LADAINHA EM } \\
\text { PORTUGUES }\end{array}$ \\
\hline Mater criato:rio o:rai pro no:bi & Mater Creatoris, ora pro nobis & Mãe do criador, rogai por nós \\
\hline
\end{tabular}

Assim como Jurussaca e Ano Bom, a comunidade indígena de Tremembé, no Ceará, também apresenta uma manifestação religiosa com características semelhantes à ladainha, o Torem, em que se mesclam palavras indígenas com palavras do português arcaico (Oliveira, Praça, 2013).

\section{Conclusáo}

A pesquisa objetivou analisar a ladainha entoada na festa de todos os Santos na comunidade quilombola de Jurussaca, buscando responder a três questionamentos: os cantadores da ladainha apenas balbuciam os sons que foram transmitidos a eles, cantam levando em consideração a língua original, que é o latim, ou cantam essa ladainha em português?

Os resultados apontam que:

A ladainha entoada em Jurussaca é transmitida exclusivamente por via oral, seguindo uma tradição em que os mais velhos transmitem para os mais novos, ou seja, é transmitida de uma geração para a outra.

$\mathrm{Na}$ festa de Todos os Santos a ladainha náo é entoada na língua falada pelos moradores de Jurussaca, os cantadores utilizam o que Silveira, Agostinho, Bandeira, Freitas, Araújo (2013) chamam de língua de cerimônia, o latim, língua tradicionalmente utilizada na tradiçáo católica - é a língua oficial do Estado do Vaticano - em ritos especiais.

E o que mais impressionou foi a fidedignidade ao texto original em latim, apesar de terem sido encontradas palavras tanto em latim quanto em português, o que mostra a força da tradição oral em comunidades tradicionais como Jurussaca.

Conclui-se que a tradição oral reflete não somente a comunicaçáo diária entre moradores das comunidades. A ladainha (Jurussaca) e outros textos religiosos de tradição católica (Ano Bom e Tremembé), transmitidos basicamente por meio oral, carregam em si não só elementos da cultura e tradição portuguesas, "[...] que lhe conferem a maior parte de suas características [...] [e] relacionam-se diretamente com a história [...]" (Calvet, 2011, p. 45), mas também elementos relacionados às comunidades, como sua identidade cultural, marcada pela sabedoria dos ancestrais e anciãos, considerados a memória viva da comunidade. 
A ladainha e a Festa de Todos os Santos na comunidade quilombola...

\section{Referências}

ALMEIDA, D. S. Família Araújo. 2010. Disponível em: http://www.webartigos. com/artigos/familia-araujo/38058/. Acesso em: 8 mar. 2013.

ARANHA SILVA, R. A. de S. O discurso do mestre-de-cerimônias: perspectiva dialógica. Mestrado em linguística aplicada e estudos da linguagem. Pontifícia Universidade Católica de São Paulo. São Paulo. 2007. Disponível em: http://www4. pucsp.br/pos/lael/lael-inf/teses/renata_almeida_souza.pdf. Acesso em: 06 jun. 2013.

BASADONNA, G., CANTARELLI, G. Ladainhas de Nossa Senhora. São Paulo: Edições Loyola. 2000.

BENVENISTE, E. Problemas de Lingüística Geral I. 5 ed. Campinas: Pontes. 2002.

BEZERRA NETO, J. M. Escravidão Negra no Grão-Pará (Sécs. XVII - XIX). Belém: Paka-Tatu. 2001.

BONVINI, E. Textos orais e textura oral. In Queiroz, S. (Org). A tradição oral. Belo Horizonte, FALE/UFMG. 2006.

BONVINI, E. Línguas africanas e português falado no Brasil. In FIORIN, J. L., PETTER, M. (orgs.). África no Brasil: a formação da língua portuguesa. São Paulo: Ed. Contexto. pp. 15-73. 2008.

BOURDIEU, P. A Economia das Trocas Lingüísticas: O que Falar Quer Dizer. Trad. Sergio Miceli, Mary Amazonas Leite de Barros, Afrânio Catani, Denice Bárbara Catani, Paula Montero e José Carlos Durand. 2 ed. São Paulo: Editora da Universidade de São Paulo. 1998. In Aranha Silva, R. A. de S. O discurso do mestrede-cerimônias: perspectiva dialógica. 2007. Mestrado em linguística aplicada e estudos da linguagem. Pontifícia Universidade Católica de São Paulo. São Paulo: 2007.

CALVET, J. Tradição oral e tradição escrita. São Paulo. Parábola Editorial. 2011.

CUNHA, A. G. Dicionário histórico das palavras portuguesas de origem tupi. São Paulo, Companhia Melhoramentos: Brasília. 1998.

FIGUEIREDO, C. G., OLIVEIRA, M. S. D. Português do Município do Libolo, Angola, e Português Afro-indígena da Comunidade de Jurussaca, Brasil: Cotejando os Sistemas de Pronominalização. São Paulo: PAPIA, v. 23, n. 2, pp. 105-185, 2013.

HOUIS, Maurice. Anthropologie linguistique de l'Afriquenoire, Paris, 1971, p. 46 In CALVET, J. Tradição oral e tradição escrita. São Paulo. Parábola Editorial. 2011.

Ladainha de Nossa Senhora em Português e Latim. Disponível em: http:// gstomasdeaquino.blogspot.com.br/2012/05/ladainha-de-nossa-senhora-emportugues.html. Acesso em: 10 jul. 2013.

LEANDRO, L. M. de L., SILVA, F. C. A estrada de ferro de Bragança e a colonização da zona bragantina no estado do Pará. Belém: UFPA. Novos Cadernos NAEA, v. 15, n. 2, pp. 143-174, 2012. 
LUCCHESI, D. A transcrição de textos orais. Disponível em: http://www.vertentes. ufba.br/projeto/transcrição. Acesso em: 18 jun. 2012.

MONTENEGRO, A. T. História Oral e memória: a cultura popular revisitada. São Paulo: Contexto. 1994. In: OLIVEIRA, E. S. Da tradição oral à escritura: a história contada no quilombo Curiaú. Dissertação (mestrado em linguística), Universidade Estadual de Campinas. Campinas. 2006.

NASCIMENTO, A. C. S., DANTAS, F. P., LUZ, M. E. M. A trajetória histórica da comunidade quilombola Jurussaca no município de Tracuateua e sua utilização em sala de aula. Bragança: Universidade Estadual Vale do Acaraú. (Trabalho de Conclusão de Curso). 2008.

O'DWYER, E. C. Introdução In O'DWYER, E. C. (Org.). Quilombos: identidade étnica e territorialidade. Rio de Janeiro: Editora FGV, 2002.

OLIVEIRA, M., PRAÇA, W. Workshop "Contatos Afro-Latinos: Perspectivas Histórico-Linguísticas". UNICAMP/IEL 26-27 de Junho de 2013. 2013.

OLIVEIRA, E. S. Da tradição oral à escritura: a história contada no quilombo Curiaú. Dissertação (mestrado em linguística), Universidade Estadual de Campinas. Campinas. 195p. 2006.

PENA, R. A. O fenômeno católico em foco: uma etnografia da festa de Nossa Senhora da Conceição Vila do Buritizal/Bailique-AP. Dissertação (mestrado integrado em desenvolvimento regional). Fundação Universidade Federal do Amapá. 140 p., 2014.

PETTER, M. M. T., OLIVEIRA, M. S. D. Levantamento etnolinguístico de comunidades afro-brasileiras de Minas Gerais e Pará. 2011. Disponível em: http:// www.fflch.usp.br/dl/indl/Extra/Projeto_Iphan_USP.htm. Acesso em: 14 jun. 2011.

PETTER, M. M. T., OLIVEIRA, M. S. D. de. Projeto-piloto IPHAN/USP. 2011 a. Disponível em: http://www.fflch.usp.br/dl/indl/Extra/Projeto_Iphan_USP.htm. Acesso em: 10 mai. 2011.

PINTO, M. C. B. V. Remanescentes quilombolas de Jurussaca - processos identitários. In: CUNHA, A. S. A. (org.). Entendendo quilombos, desconstruindo mitos - a educação formal e a realidade quilombola no Brasil. Guimarães, MA: SETAGRAF, pp. 129-144. 2011.

QUEIROZ, S. (org). A tradição oral. Belo Horizonte, FALE/UFMG. 2006.

SILVA, G. Transcrição da Ladainha de Nossa Senhora em Jurussaca. Manuscrito. 2013.

SILVEIRA, A. C., AGOSTINHO, A. L. dos S., BANDEIRA, M., FREITAS, S., ARAÚJO, G. A. Fa d'ambô: língua crioula de Ano Bom. Cadernos de Estudos Lingüísticos, v. 55, n. 2, Campinas, pp. 25-44, 2013.

SOUZA, M. da G. M. Análise Crítica do Ofício Divino das Comunidades. (Tese de Doutorado) Pontifícia Universidade Católica de São Paulo. 2011. 
A ladainha e a Festa de Todos os Santos na comunidade quilombola...

Disponível em: http://www.sapientia.pucsp.br/tde_arquivos/34/TDE-2011-1025T07:59:56Z-1 1671/Publico/Maria\%20da\%20Gloria\%20Melo\%20de\%20Souza. pdf. Acesso em: 26 ago. 2013.

VANSINA, Jan. A tradição oral e sua metodologia. História geral da África, v. 1, pp. 157-179, 2010.

VAZ, J. C. O Louvor a Maria. Ediçóes Loyola. 2005.

Recebido em: 29/03/2020

Aprovado em: 04/03/2021

Conflito de interesses: Não declarado pelo autor.

Este artigo foi avaliado e aceito por dois pareceristas diferentes.

Editor: Antonio Genivaldo C. de Oliveira 